\title{
FORMAÇÃO CONTINUADA DE PROFESSORES: RACIONALIDADE TÉCNICA VERSUS DESENVOLVIMENTO PROFISSIONAL ${ }^{1}$
}

\author{
FORMACIÓN CONTINUA DEL PROFESORADO: LA RACIONALIDAD \\ TÉCNICA VERSUS DESARROLLO PROFESIONAL
}

\author{
CONTINUING EDUCATION OF TEACHERS: TECHNICAL \\ RATIONALITY VERSUS PROFESSIONAL DEVELOPMENT
}

\author{
Rayane Regina Scheidt GASPARELO ${ }^{2}$ \\ Marisa SCHNECKENBERG ${ }^{3}$
}

\begin{abstract}
RESUMO: Este ensaio surgiu a partir de reflexões teóricas, com o objetivo de evidenciar os principais debates conceituais e metodológicos para a proposição da formação continuada dos professores, nos últimos anos. Pérez-Gómez (1995) destaca que a formação de professores é determinada pela concepção de escola, ensino e currículo adotados ao longo da história, e que há duas concepções básicas na forma de conceber a intervenção educativa e, em específico a atividade do professor como profissional de ensino, responsável pela natureza e qualidade do quotidiano educativo na sala de aula e na escola, são elas: o professor como técnico-especialista ou o professor como prático reflexivo que analisa e problematiza a sua própria ação. Portanto, a perspectiva técnica e a perspectiva do desenvolvimento profissional são as basilares que marcam o campo das discussões sobre formação continuada.
\end{abstract}

PALAVRAS-CHAVE: Formação Continuada. Capacitações Docentes. Desenvolvimento profissional.

RESUMEN: Esta prueba surgió a partir de reflexiones teóricas, con el fin de destacar los principales debates conceptuales y metodológicos, a la propuesta de la educación permanente de los profesores en los últimos años. Pérez-Gómez (1995) señaló que la capacitación de los maestros es determinado por el diseño del currículo escolar, la enseñanza y aprobada en el curso de la historia, Y que hay dos concepciones básicas en la forma de diseñar intervenciones educativas $y$, específicamente, la actividad de los maestros como un profesional de la educación, responsable de la naturaleza y la calidad de la educativa diaria en el aula y en la escuela, son: el profesor como técnico especialista o el profesor como práctica reflexiva que examina y discute su propia acción. Por lo tanto, la perspectiva técnica y la perspectiva de desarrollo profesional

\footnotetext{
${ }^{1}$ Parte de estudo realizado para Dissertação de Mestrado em Educação.

${ }^{2}$ Universidade Estadual de Campinas (Unicamp), Campinas - SP - Brasil. Doutoranda em Educação LAGE (Laboratório de Gestão Educacional). Docente na Universidade Estadual de Ponta Grossa. E-mail: rayanegasparelo.0706@gmail.com.

${ }^{3}$ Universidade do Centro-Oeste (Unicentro) - PR - Brasil. Docente do Curso de Pedagogia e do Programa de Pós-Graduação em Educação. Doutora em Educação e Orientadora na linha de Pesquisa: Políticas Educacionais, história e organização da educação - PPGE/UNICENTRO. E-mail: marisas@irati.unicentro.br.
} 
son las piedras angulares que marcan el campo de debate acerca de la educación continua.

PALABRAS CLAVE: La educación continua. Formación de professores. Desarrollo profesional.

ABSTRACT: This test emerged from theoretical reflections, with the aim of highlighting the main debates conceptual and methodological to the proposition of continuous education of teachers in recent years. Pérez-Gómez (1995) noted that teacher training is determined by the design of school, teaching and curriculum used throughout history, and that there are two basic conceptions in the form of designing educational interventions, and specifically the activity of teachers as a professional education, responsible for the nature and quality of daily educational in the classroom and in school, they are: the teacher as a technical-specialist or the teacher as reflective practice that examines and discusses its own action. Therefore, the technical perspective and the perspective of professional development are the cornerstones that mark the field of discussion about continued education.

KEYWORDS: Continued education. Training teachers. Professional development.

\section{Considerações iniciais}

Na LDBEN 9.394/96 (BRASIL, 1996) a formação continuada está explicitada no artigo 62-A, parágrafo único, ficando claro que é um processo que pode ser realizado no local de trabalho ou em instituições de educação básica e superior. Tal orientação legal é reforçada na Meta 16 do Plano Nacional de Educação - PNE (2014-2024). Nesta propõe-se,

Formar, em nível de pós-graduação, cinquenta por cento dos professores da educação básica, até o último ano de vigência deste PNE, e garantir a todos(as) os(as) profissionais da educação básica formação continuada em sua área de atuação, considerando as necessidades, demandas e contextualizações dos sistemas de ensino. (BRASIL, 2014)

Assim, faz-se necessário que os agentes escolares estejam completamente envolvidos com a formação continuada em nível macro (programas de governo) e em nível micro (escola), procurando associar esta prática às novas tendências que a sociedade nos apresenta.

Portanto, a formação continuada dos profissionais da educação é um dever do Estado, bem como direito e dever dos docentes. Estes, precisam constantemente refletir 
e compreender objetivamente as interferências do contexto socioeconômico, político e cultural sobre seu trabalho e a formação do aluno.

De acordo com Campos (2003) a perspectiva de educação crítica e transformadora deve reafirmar a formação de um profissional capaz de compreender, intervir e transformar, não apenas o contexto de sua escola, mas a realidade que está inserido.

Contudo, considerando as bibliografias do campo das discussões acadêmicas que embasam o campo conceitual e metodológico dos princípios que fundamentam os processos de formação continuada, há duas perspectivas que se opõem e precisam ser problematizadas, são elas: o professor como técnico-especialista ou o professor como prático reflexivo que analisa e problematiza a sua própria ação.

Nesta direção é que este ensaio se constitui, pois é importante evidenciar os pressupostos que podem fundamentar as políticas de formação continuada, que em tempos de reformas constantes, com mudanças bruscas nos setores socioeconômicos, políticos e culturais, mostra-se com nuances de profunda desvalorização docente.

\section{Principais discussões}

Alvarado-Prada, Freitas e Freitas (2010) explicam que historicamente, por volta dos anos 60, 70, 80 e 90, a formação continuada foi-se constituindo como produto de consumo apenas para cumprir uma exigência social. Capacitações, reciclagens e treinamentos atendendo aos interesses de governantes e das reformas, traziam pouco ou nenhum resultado para o sucesso nas formas de organização escolar e do trabalho pedagógico, pois desconsideravam as características dos professores, suas necessidades e expectativas pessoais e profissionais, seus contextos de trabalho, bem como a cultura elaborada pela instituição escolar em que eles atuavam.

Desse contexto, Pérez-Gómez (1995) afirma que nos últimos trinta anos a formação dos docentes pautava-se na concepção tecnológica da atividade profissional (prática), ou seja, a atividade do profissional é antes de tudo instrumental, direcionada para a solução de problemas a partir da aplicação rigorosa de princípios, técnicas e conhecimentos gerais. Nesse cenário, Imbernón (2009) destaca que a formação continuada atendia o modelo aplicacionista-transmissivo, normalmente com cursos de curta duração que encaminhavam lições modelo e competências necessárias para ser um bom docente. 
Campos (2003) complementa apontando que a formação docente cooperava significativamente para a construção da representação do professor competente encobrindo a representação do professor reflexivo. Desta maneira, se fizesse uma análise rigorosa nos programas de formação permanente do professorado até os anos 2000, “[...] permitiria lançar alguns deles ao cesto do lixo”. (IMBÉRNON, 2009, p. 13). Nessa proposta,

\begin{abstract}
A formação de professores é entendida fundamentalmente como um processo de socialização e indução profissional na prática quotidiana da escola, não se recorrendo ao apoio conceptual e teórico da investigação científica, o que conduz facilmente à reprodução dos vícios, preconceitos, mitos e obstáculos epistemológicos acumulados na prática empírica. (PÉREZ-GÓMEZ, 1995, p. 99).
\end{abstract}

A perspectiva da racionalidade técnica pressupõe então, que a realidade social pode ser encaixada em esquemas preestabelecidos, não havendo complexidades, singularidades, incertezas e conflitos de valores. A formação dos docentes é impregnada de uma concepção linear e simplista dos processos de ensino.

Ainda sobre a formação nesse período, Campos (2003) pondera que o princípio técnico-profissionalizante surgiu com as reformas que priorizavam a lógica empresarial, ou seja, a educação, em suas diferentes dimensões (currículo, avaliação, gestão, financiamento) precisava ser adequada aos imperativos economicistas que conduzia as políticas públicas. Assim, cabia aos docentes impulsionar a eficácia dos sistemas educativos preparando os alunos para atuar no mercado de trabalho de acordo com as exigências da modernidade.

Contudo, embora desde o sec. XX os contextos já estivessem mudando com a influência política, econômica, cultural e tecnológica e condicionando a formação docente, a chegada do séc. XXI, de acordo com Imbérnon (2009), é como se faltasse algo para que a formação, seja inicial ou continuada, se tornasse um meio para promover a inovação no processo de ensino-aprendizagem dos alunos, na busca de novos conhecimentos teórico-metodológicos para o desenvolvimento profissional e a transformação de práticas pedagógicas. Precisava-se ir além da formação igual para todos, gestão idêntica para todas as instituições, currículo mascarado, dentre outras formas que conduzem a um pensamento educativo único predominante. Visto que,

De modo geral, na prática não existem problemas, mas sim situações problemáticas, que se apresentam frequentemente como casos únicos que não se enquadram nas categorias genéricas identificadas pela 
técnica e pela teoria existente. Por essa razão, o profissional prático não pode tratar estas situações como se fossem meros problemas instrumentais, susceptíveis de resolução através da aplicação de regras armazenadas no seu próprio conhecimento científico-técnico. (PÉREZ-GÓMEZ, 1995, p. 100).

Com esta premissa, pode-se considerar que a atividade prática do professor é uma atividade que requer reflexão diante das manifestações mais peculiares do ensino. Reflexão, que segundo Pérez-Gómez (1995, p. 103) “[...] implica a imersão consciente do homem no mundo da sua experiência, um mundo carregado de conotações, valores, intercâmbios simbólicos, correspondências afectivas, interesses sociais e cenários políticos".

De acordo com Nadal (2000), durante as práticas de formação continuada (cursos, projetos de investigação, grupos de estudo, rodas de discussão) do agente educativo, é importante que os formadores sejam facilitadores e viabilizadores do processo de investigação-ação dos docentes e que as finalidades e os conteúdos do ensino sejam objetos de constante estudo e reflexão, considerando o contexto em que esse trabalho acontece. Para a autora, resgatando o processo de reflexão da e na prática, a partir da valorização dos saberes práticos, busca-se na formação a unidade teoriaprática.

Nesse processo, a prática seria objeto de reflexão contínua a fim de torná-la uma prática social ética cujo objetivo é, por meio do ensino, desenvolver a consciência dos sujeitos visando a transformação social a partir da superação das desigualdades sociais.

Para Schön (1995) a formação continuada precisa colaborar sistematicamente com a formação do professor reflexivo, conforme afirma, ao propor uma formação baseada na valorização da prática profissional como momento de construção de conhecimento por meio de reflexão, análise e problematização dessa prática. Nesse mesmo viés, Pimenta e Lima (2008) referem-se à formação fundamentada na 'epistemologia da prática', na qual:

É possibilitado pela atividade de pesquisa, que se inicia com a análise e problematização das ações e das práticas, confrontadas com as explicações teóricas sobre estas, com experiência de outros atores e olhares de outros campos de conhecimento, com os objetivos pretendidos e com as finalidades da educação na formação da sociedade humana. (PIMENTA; LIMA, 2008, p. 49-50).

Assim, é essencial que os professores compreendam a articulação reflexão-ação 
e tenham nos programas de formação continuada, seja na escola ou nas políticas para a gestão educacional recursos e tempo necessário para que possam compreender a realidade institucional, analisá-la e possivelmente transformá-la a partir da sua prática pedagógica.

Alarcão (2007, p. 41) sobre a noção de professor reflexivo assinala que a mesma, "[...] baseia-se na consciência da capacidade de pensamento e reflexão que caracteriza o ser humano como criativo e não como mero reprodutor de ideias e práticas que lhe são exteriores”.

Shön (2000) explicita que ao cunhar a ideia de formação do professor reflexivo propõe uma formação desprendida de um currículo normativo, que contempla a prática para um último momento e prioriza a ciência. Para o autor, o conhecimento é obtido pela reflexão, a partir dos problemas que surgem na prática.

Pimenta e Lima (2008) também consideram de extrema importância a reflexão sobre e na prática, contudo alertam que essa perspectiva precisa ser analisada contextualizadamente, visto que há limites de natureza política e teórico-metodológica na formação do professor reflexivo, como as condições de espaço para reflexão e pesquisa que a escola pública oferece; corpo docente rotativo; limites na formação inicial - aligeirada e frágil teórica e praticamente; possibilidades efetivas do professor investigar a prática; aportes teóricos e metodológicos para o desenvolvimento de pesquisa, o individualismo da reflexão, a ausência de critérios externos potencializadores de uma reflexão crítica, excessiva ênfase nas práticas, entre outros. Desconsiderar estes condicionantes pode gerar um discurso de culpabilização dos professores, praticismo e individualismo, reduzindo a pesquisa sobre a prática aos problemas pedagógicos. Portanto, faz-se necessário reconhecer que o conceito de professor reflexivo é um “[...] conceito político-epistemológico que requer o suporte de políticas públicas consequentes para sua efetivação". (PIMENTA; LIMA, 2008, p. 54).

Pimenta (2012) a partir dessas críticas aponta um conjunto de possibilidades de superação desses limites, que consiste em: construir conhecimentos com a análise crítica (teórica) das práticas e ressignificação das teorias a partir dos conhecimentos da prática (práxis), ou seja, da epistemologia da prática à práxis; da perspectiva do professor reflexivo ao intelectual crítico reflexivo, quer dizer, da dimensão individual da reflexão ao seu caráter público e ético; do professor-pesquisador à realização da pesquisa no espaço escolar como integrante da jornada de trabalho dos profissionais da escola, com a colaboração de pesquisadores da universidade; da formação inicial e dos programas de 
formação contínua, que podem significar um deslocamento da escola, aprimoramento individual e corporativismo, ao desenvolvimento profissional e da formação contínua que investe na profissionalização individual ao reforço da escola e do coletivo no desenvolvimento profissional dos professores.

Considerando estas críticas, mas sendo indiscutível a contribuição da perspectiva reflexiva, Libâneo (2012) caracteriza dois tipos básicos de reflexividade: a reflexividade de cunho neoliberal e a reflexividade de cunho crítico. Nas considerações do autor:

No campo neoliberal, o método reflexivo situa-se no âmbito do positivismo, do neopositivismo ou, ainda, do tecnicismo, cujo denominador comum é a racionalidade instrumental. No campo crítico, fala-se da reflexividade crítica, crítica reflexiva, reconstrucionista social, comunicativa, hermenêutica, comunitária. (LIBÂNEO, 2012, p. 73).

Com esse entendimento, tanto Pimenta (2012) como Libâneo (2012) apontam para uma proposta que considera na formação o professor crítico reflexivo ou intelectual crítico e reflexivo superando a identidade dos professores de reflexivos.

Diante disso, embora os condicionantes de ordem político, social e organizacional exerçam influência e limites na formação contínua,

Sugerir uma formação contínua a partir de uma visão crítica e reflexiva é possibilitar o aprendizado dos professores por um caminho emancipatório e apreensivo da realidade, além de conscientizá-los da transformação do mundo como ato político. (SILVA, 2011, p. 5).

Portanto, há que se reconhecer que,

A partir das propostas de professor reflexivo e suas práticas de reflexividade, começam a surgir novas leituras sobre o papel desse profissional e quem é ele, valorizando suas formas de expressão, pensamento, cultura, crenças e valores. Sua identidade adquiriu o sentido de que ele é sujeito e não mero executor das funções de ensino-aprendizagem. Na escola, também passa a fazer parte das ações comunitárias, gestão democrática, construção e análise dos currículos, participação no desenvolvimento da proposta pedagógica, organização dos tempos e espaços escolares, desvinculando, assim, a visão única de professor e sala de aula. (SILVA, 2011, p. 5).

Metaforicamente, "[...] Como diria um treinador de futebol, recuperar a vontade de jogar e o protagonismo (os jogadores) merecido". (IMBÉRNON, 2009, p. 36). Assim 
sendo, ao nível da formação continuada é possível a construção de uma escola viva e vivificante, desde que a partilha de experiências e a investigação-ação conduzam a formação de uma nova práxis.

Pérez-Gómez (1995) destaca que as discussões acerca da formação do professor reflexivo tendo como eixo central do processo de 'reflexão-na-ação' abordado por Donald A. Shön $(1995 ; 2000)$ surgiu para superar a relação linear e mecânica entre o conhecimento científico-técnico e a prática de sala de aula. Portanto, neste modelo de formação a prática é o eixo central de todo o currículo, lugar de aprendizagem e construção do pensamento prático do professor, que envolve conhecimento na ação, reflexão na ação, reflexão sobre a ação e sobre a reflexão na ação. Em síntese,

O conhecimento na ação se manifesta no saber fazer, é o conhecimento tácito, sendo mobilizado pelos professores no seu dia-adia, não estando implícito somente na atividade prática. Constantemente, os professores se veem criando, construindo outras soluções que fogem da rotina, favorecendo o processo de reflexão na ação, na qual frequentemente pensam e fazem ao mesmo tempo em que atuam. A reflexão sobre a reflexão na ação é a análise que o sujeito faz após a ação, ou seja, para superar as novas situações ele busca outras opções, pesquisas ou investigações que possam ajudá-lo. (SILVA, 2011, p. 5).

Portanto, a formação contínua precisa caracterizar-se como um processo de investigação-ação a partir da prática pedagógica. Nessa perspectiva, "[...] não se trata de mobilizar a experiência apenas numa dimensão pedagógica, mas também num quadro conceptual de produção de saberes". (NÓVOA, 1995, p. 25).

Todavia, Imbernón (2009) avalia que contemporaneamente há muita formação, mas poucas mudanças e inovações, pois ainda predominam nas políticas e nos formadores práticas de formação transmissora e uniforme de teorias descontextualizadas e baseadas em uma problemática sempre comum, distantes dos problemas práticos do professorado.

Pimenta e Lima (2008) nessa questão caracterizam essa perspectiva como 'formação (des)contínua baseada no mito metodológico'. Nesta, tanto os professores como as políticas governamentais de formação, investem com bastante afinco, tempo e recursos financeiros para o conhecimento de técnicas e métodos universais para solucionar as lacunas da profissão e do ensino, sem estabelecer nexos entre as teorias e a realidade nas quais a docência ocorre. Nesta, "[...] a maior parte das atividades de formação contínua para os professores são fatos esporádicos, no lugar de experiências 
de aprendizagem evolutivas". (VAILLANT; MARCELO, 2012, p. 172).

Nesse cenário Ball (2005) assegura:

\begin{abstract}
Os professores acabam inseridos na performatividade pelo empenho com que tentam corresponder aos novos (e às vezes inconciliáveis) imperativos da competição e do cumprimento de metas. Os compromissos humanísticos do verdadeiro profissional - a ética do serviço - são substituídos pela teleológica promiscuidade do profissional técnico - o gerente. A eficácia prevalece sobre a ética; a ordem, sobre a ambivalência. Essa mudança na consciência e na identidade do professor apóia-se e se ramifica pela introdução, na preparação do professor, de formas novas de treinamento não intelectualizado, baseado na competência. (BALL, 2005, p. 548)
\end{abstract}

Numa perspectiva contrária, de valorização da experiência e a reflexão na experiência, as ações delineadas para os momentos definidos de formação continuada contemplariam um movimento dialético de análise e problematização das ações dos sujeitos e práticas institucionalizadas, contrastando com explicações teóricas de autores e os propósitos da educação na formação do sujeito. Necessariamente,

Uma proposta metodológica para formação contínua precisa dar o salto de superação dos recursos metodológicos para uma postura metodológica, fundamentada em três pilares: a análise da prática docente, a relação teoria-prática e o trabalho docente nas escolas como categoria principal dessa atividade. Em suma, prática, reflexão teórica e prática refletida, analisada e contextualizada [...]. (PIMENTA; LIMA, 2008, p. 134, grifo do autor).

Nesse sentido, objetiva-se com a prática-reflexiva ultrapassar o modelo de formação continuada pautada pela racionalidade técnica, dimensão na qual os docentes são simples implementadores de roteiros curriculares com orientações que são uniformes para todas as instituições educativas. "[...] Esta racionalidade técnica contraria uma perspectiva de (re)profissionalização e representa uma visão restrita do profissionalismo docente.” (FLORES, 2003, p. 130).

Sobre essa questão Bourdieu (2013, p. 207) assegura:

Pode-se admitir que a prática implica sempre uma operação de conhecimento, isto é, uma operação mais ou menos complexa de classificação, que nada tem em comum com um registro passivo, sem, no entanto, fazer disto uma construção puramente intelectual; o conhecimento prático é uma operação prática de construção que aciona, por referência a funções práticas, sistemas de classificação 
(taxinomias) que organizam a percepção e a apreciação, e estruturam a prática.

Ao considerar que na prática docente há um conhecimento construído resultante de fatores cognitivos, afetivos, explicativos, normativos e que a docência não se resume à aplicação de procedimentos e recursos técnicos de intervenção, as dificuldades dessa prática podem mobilizar a reflexão docente.

Nesse processo, a prática seria objeto de reflexão contínua a fim de torná-la uma prática social ética cujo objetivo, por meio do ensino, seria desenvolver a consciência crítica dos sujeitos sobre as diversas transformações sociais que ocorrem no meio.

Desta forma,

É importante que, durante o processo reflexivo, se trabalhe com as teorias produzidas por pesquisadores, mas que, também se considerem as experiências e saberes do próprio professor, evitando que a reflexão se destine somente a "vender" a ele teorias prontas. Uma reflexão efetiva deve procurar sobressair-se pela elaboração do professor, tornando-o um elemento ativo no processo. (NADAL, 2000, p. 19-20).

Nessa perspectiva, ao professor é atribuída uma reflexão fundamentada sobre suas práticas, propiciando o desenvolvimento pessoal/profissional ${ }^{4}$ e em consequência o desenvolvimento institucional/organizacional da escola como um todo. Pois, “[...] poucos estariam dispostos a negar que o desenvolvimento profissional do professor e o aperfeiçoamento da instituição escolar são duas faces da mesma moeda, de tal forma é difícil pensar numa sem a outra”. (GARCÍA, 1999, p. 139).

Sob a concepção de formação para o desenvolvimento profissional dos professores García (1999) acredita ser uma abordagem na formação de docentes que reconhece e valoriza o seu carácter contextual, organizacional e orientado para mudança, na qual não só o professor como todos aqueles com responsabilidade e implicação no aperfeiçoamento da escola, envolvem-se em atitude de pesquisa, questionamento e busca de soluções para todas as questões pertinentes à escola. “[...] Quer isso dizer que o desenvolvimento do professor não ocorre no vazio, mas inserido num contexto mais vasto de desenvolvimento organizacional e curricular." (GARCÍA, 1999, p. 139). Assim, não se trata de reduzir a formação à uma etapa meramente informativa de pouco ou nenhum impacto às necessidades pessoais, profissionais e

\footnotetext{
${ }^{4}$ Nóvoa (1995) sublinha que os percursos pessoais e profissionais quando relembrados numa atitude avaliativa estão articulados e conduzem para momentos em que cada docente produz a sua vida e a sua profissão.
} 
organizacionais.

A noção de 'desenvolvimento' pressupõe conceber a formação de professores como um continuum, ou seja, formação inicial e formação continuada interconectadas num movimento de evolução e continuidade, analisando as causas e consequências da conduta docente. Desse ponto de vista, “[...] o desenvolvimento profissional caracterizase por uma atitude permanente de indagação, de formulação de perguntas e problemas e a busca de suas soluções". (VAILLANT; MARCELO, 2012, p. 167).

Portanto, o desenvolvimento profissional implica em uma constante revisão e renovação de práticas educativas a partir de experiências de aprendizagem evolutivas e acumulativas. Consiste na melhoria do conjunto de prestações de ensino.

Desta forma, “a investigação-acção contribui para o desenvolvimento profissional, na medida em que luta por um professor autoconsciente, comprometido com a escola e com a sua profissão, capaz de gerar conhecimento através da sua própria análise e reflexão (individual e colectiva)." (GARCÍA, 1999, p. 186).

Nessa mesma concepção, Flores (2003) destaca que ao valorizar a prática como fonte e local de aprendizagem através da reflexão e da investigação, os docentes refletem sobre os propósitos e valores implícitos em suas práticas, (re)construindo a profissionalização ${ }^{5}$ e o profissionalismo ${ }^{6}$ docente.

Nessa dinâmica, práticas e teorias se entrelaçam e se complementam permitindo questionar e refletir sobre as práticas institucionalizadas e as ações pedagógicas realizadas nos contextos escolares, “[...] porque na ação profissional coexistem a ação e o discurso sobre a ação. Sabe-se que os professores podem conseguir ser melhores profissionais refletindo sobre o que fazem”. (GARCÍA, 1999, p.185). Assim,

Urge procurar um tipo de formação, a formação centrada na escola, como organização que aprende, contextualizada, vivenciadora de projetos, fator de desenvolvimento pessoal e profissional dos professores. Partindo dos projectos educativos de escola, teríamos de conceber a escola como unidade de mudança, sendo o professor encarado como construtor e gestor de currículos inovadores, como autor da sua formação. (SILVA, 2003, p. 119).

Considerando a escola como ponto de partida e de chegada, pautada em um projeto educativo cuja formação seja para superação das desigualdades sociais, a formação contínua intencionada seja nos programas de governo como na própria

\footnotetext{
${ }^{5}$ Projeto ou processo político ou social que busca o reconhecimento da profissão e do profissional.
}

${ }^{6}$ Atenção para a natureza e qualidade do trabalho desenvolvido. 
instituição educativa, precisa incluir sistematicamente ações para o desenvolvimento profissional dos professores, considerando a perspectiva do professor individual e do coletivo docente e os projetos das escolas, possibilitando que os docentes investiguem a própria atividade pedagógica como compromisso profissional para perceber a dimensão social da profissão docente.

Assim, o conceito de desenvolvimento profissional projeta na formação as oportunidades de aprendizagens para melhorar as práticas, buscando promover nos docentes, capacidades criativas e reflexivas para que respondam às demandas do trabalho diário.

Para tanto,

É necessário que os professores deixem de se limitar a cumprir aquilo que lhes é prescrito, se empenhem numa contínua renovação e (re)valorização científica e pedagógica e se assumam como profissionais autónomos que tomam decisões em prol do conjunto concreto de alunos com que trabalham. (MORGADO, 2011, p. 808).

Nesse quadro, o profissional do ensino diferentemente do técnico do ensino:

Trata não só de 'fazer' ou implementar um determinado currículo, mas de tomar decisões, de emitir juízos fundamentados, de compreender e justificar as próprias ações e de refletir sobre os contextos educacionais nos quais se exerce a atividade docente. (FLORES, 2003, p. 139).

Em outras palavras, conceber a formação continuada não como obrigatória, somente para ascensão na carreira, mas como condição para avaliação do seu desempenho profissional e contínuo (re)pensar da profissionalidade ${ }^{7}$ docente.

Nessa questão, Nóvoa (1995) aponta que na profissão docente confrontam-se dois processos: a profissionalização e a proletarização. O primeiro refere-se ao processo no qual os docentes melhoram seu estatuto e aumentam o seu poder/autonomia. Já a proletarização, provocado pelo excesso de trabalho diário, sobrecarga permanente de atividades, execução de técnicas e padronização de tarefas priorizando a quantidade e não a qualidade do ensino causando uma degradação do estatuto, rendimento e poder/autonomia dos professores. A tendência no sentido de intensificação do trabalho dos professores contribui para o processo de desprestígio da experiência e das

7 Conjunto de características essenciais, conhecimentos, destrezas, atitudes e valores específicos da profissão. (FLORES, 2003; SACRISTÁN, 1995; PAPI, 2005). 
capacidades adquiridas no decorrer dos anos. Nesse sentido, a formação de professores precisa “[...]desempenhar um importante papel na configuração de uma nova profissionalidade docente, estimulando a emergência de uma cultura profissional no seio do professorado e de uma cultura organizacional no seio das escolas". (NÓVOA, 1995, p. 24).

Dessa forma, a formação contínua, de acordo com Pimenta e Lima (2008) é assumida como atitude de vida e de profissão, constituindo um movimento constante de autoformação da postura conceitual metodológica. "[...] Porque contínuo é o homem, e não o curso [...].” (PIMENTA; LIMA, 2008, p. 141).

Com esta mesma compreensão Imbernón (2009, p. 48) assinala:

\begin{abstract}
Isso abrange uma mudança radical da forma de pensar a formação, já que não supõe tanto o desenvolvimento de modalidades centradas nas atividades da aula, nem ver o(a) professor(a) como um aplicador de técnicas pedagógicas, mas privilegia o comprometimento com uma formação orientada para um sujeito que tem capacidades de processamento da informação, analise e reflexão crítica, decisão racional, avaliação de processos e reformulação de projetos, tanto trabalhistas como sociais e educativos em seu contexto e com seus colegas.
\end{abstract}

Para tanto, é um grande equívoco reduzir a formação contínua à cursos, miniaulas, oficinas pedagógicas voltadas para confecção de recursos didáticos e habilidades instrumentais. O processo educativo é amplo e complexo, requer ações refletidas sobre as práticas docentes para que no redimensionamento das mesmas o professor possa ser agente de mudanças na escola e na sociedade. Visto que, de acordo com Pimenta e Lima (2008) a ação pedagógica é determinada, mas, também determinante da prática institucionalizante.

Para Imbernón (2009, p. 47),

A formação permanente deveria apoiar-se, criar cenários e potencializar uma reflexão real dos sujeitos sobre sua prática docente nos centros e nos territórios, de modo que lhes permita examinar suas teorias implícitas, seus esquemas de funcionamento, suas atitudes etc., potencializando um processo constante de autoavaliação do que se faz e analisando o porquê se faz.

A formação permanente deveria apoiar-se, criar cenários e potencializar uma reflexão real dos sujeitos sobre sua prática docente nos centros e nos territórios, de modo que lhes permita examinar suas teorias implícitas, seus esquemas de 
funcionamento, suas atitudes etc., potencializando um processo constante de autoavaliação do que se faz e analisando o porquê se faz.

Ao refletir sobre a sua própria prática, ao identificar e diagnosticar problemas que nela ocorrem, ao se colocar intencionalmente a possibilidade de intervir em tal situação utilizando metodologias apropriadas, o professor converte-se em investigador da sua própria prática, desenvolve o seu profissionalismo e competência epistemológica. (GARCÍA, 1999, p. 183).

Nesta linha, as práticas de formação de professores orientadas para mudanças/alterações das práticas que constituem a educação, tornam-se um elementochave do projeto de reforma do sistema educativo.

\section{Considerações finais}

Este ensaio delineou-se com o objetivo de evidenciar os principais debates conceituais e metodológicos para a proposição da formação continuada dos professores, nos últimos anos.

Diante de tal objetivo, recorreu-se a bibliografia pertinente da área e sintetizouse as duas principais correntes teórico-metodológicas que podem embasar os percursos da formação continuada dos docentes, sendo: a perspectiva técnica e a perspectiva do desenvolvimento profissional.

Nesse universo, concordamos com Shiroma (2003) que as possibilidades de extrapolar, nos anos 2000, as fronteiras do conhecimento prático e utilitário, estão abertas, e é preciso de alguma forma ensaiá-lo, numa perspectiva, como afirma Ball (2005), diferente do profissional colonizado que apenas presta contas e responde aos requisitos externos e a objetivos específicos, equipado com métodos padronizados e adequados para qualquer eventualidade.

Para Ball (2005) a formação diferenciada teria como propósito a formação do profissional autêntico ou reorientado. Este, absorve e aprende com a reforma, mas não é fundamentalmente transformado por ela, permanecendo imóvel. [...] "Esse campo fornece uma base para reflexão, diálogo e debate. Não lhes diz o que fazer. Dá-lhes uma linguagem para pensar a sua ação e refletir sobre seu trabalho e o trabalho de outros, dentro de um relacionamento de sujeitos ativos". (BALL, 2005, p. 558)

\section{REFERÊNCIAS}


ALVARADO-PRADA, L. E.; FREITAS, T. C.; FREITAS, C. A. Formação continuada de professores: alguns conceitos, interesses, necessidades e propostas. Rev. Diálogo Educ., Curitiba, v. 10, n. 30, p. 367-387, maio/ago. 2010.

BALL, S. J. Profissionalismo, gerencialismo e performatividade. Cadernos de Pesquisa, v. 35, n. 126, p. 539-564, set./dez. 2005.

BOURDIEU, P. A escola conservadora: as desigualdades frente à escola e à cultura. In: NOGUEIRA, M. A.; CATANI, A. (Orgs). Pierre Bourdieu: escritos e educação. Petrópolis, RJ: Vozes, 2013.

BRASIL. Lei n ${ }^{\circ}$ 9.394, de 20 de dezembro de 1996. Estabelece as diretrizes e bases da educação nacional. Diário Oficial da União, Brasília, DF, 1996.

BRASIL. Lei no 13.005, de 25 de junho de 2014. Aprova o Plano Nacional de Educação - PNE e dá outras providências. Diário Oficial da União, Brasília, DF, 26 jun. 2014.

CAMPOS, R. F. Do Professor reflexivo ao professor competente: os caminhos da reforma no Brasil. In: MORAES, M. C.; PACHECO, J. A.; EVANGELISTA, M. O. (Orgs.). Formação de professores: perspectivas educacionais e curriculares. Porto: Porto Editora, 2003.

FLORES, M. A. Dilemas e desafios na formação de professores. In: MORAES, M. C.; PACHECO, J. A.; EVANGELISTA, M. O. (Orgs.). Formação de professores: perspectivas educacionais e curriculares. Porto: Porto Editora, 2003.

GARCÍA, C. M. Formação de professores para uma mudança educativa. Portugal: Porto Editora, 1999.

GARCÍA, C. M. A formação de professores: novas perspectivas baseadas na investigação sobre o pensamento do professor. In: NÓVOA, A. Os professores e a sua formação. 2. ed. Lisboa: Instituto de Inovação Educacional, 1995.

IMBERNÓN, F Formação permanente do professorado: novas tendências. São Paulo: Cortez, 2009.

LIBÂNEO, J. C.; OLIVEIRA, J. F. de; TOSCHI, M. S. Educação escolar: políticas, estrutura e organização. São Paulo: Cortez, 2012.

LIBÂNEO, J. C. Pedagogia e pedagogos, pra quê? São Paulo: Cortez, 1998.

MORGADO, J. C. Identidade e profissionalidade docente: sentidos (im)possibilidades. Ensaio: aval. pol. públ. Educ., Rio de Janeiro, v. 19, n. 73, p. 793-812, out./dez. 2011.

NADAL, B. G. Gestão e formação contínua: práticas articuladas da gestão escolar.

Olhar de Professor, Ponta Grossa, v. 3, n. 3, p. 15-28, nov. 2007.

NÓVOA, A. Formação de professores e profissão docente. In: NÓVOA, A. (Coord.). Os professores e a sua formação. 2. ed. Lisboa: Dom Quixote, 1995. 
PÉREZ-GÓMEZ, A. O Pensamento prático do professor: a formação do professor como profissional reflexivo. In: NÓVOA, A. (Coord.). Os rofessores e sua formação. 2. ed. Lisboa: Dom Quixote, 1995.

PIMENTA, S. G.; LIMA, M. S. L. Estágio e docência. São Paulo: Cortez, 2008.

SHIROMA, E. O. O eufemismo da profissionalização. In: MORAES, M. C. M. (Org.). Iluminismo às avessas: produção de conhecimento e políticas de formação docente. Rio de Janeiro: DP\&A, 2003.

SILVA, J. da C. M. Formação continuada dos professores: visando a própria experiência para uma nova perspectiva. Revista Iberoamericana de Educación, v. 3, n. 55, p. 01-11, 15 abr. 2011.

SILVA, J. N. A Formação contínua de professores: contradições de um modelo. In: MORAES, M. C.; PACHECO, J. A.; EVANGELISTA, M. O. (Orgs.). Formação de professores: perspectivas educacionais e curriculares. Porto: Porto Editora, 2003.

SCHÖN, D. A. Educando o profissional reflexivo: um novo design para o ensino e a aprendizagem. Porto Alegre: Artmed, 2000.

SCHÖN, D. A. Formar professores como profissionais reflexivos. In: NÓVOA, A. (Coord.). Os professores e sua formação. 2. ed. Lisboa. Dom Quixote, 1995. p.77-92.

SOUZA, A. R. Reformas educacionais: descentralização, gestão e autonomia escolar. Educar, Curitiba, n. 22, p. 17- 49, 2003.

VAILLANT, D.; MARCELO, C. Ensinando a ensinar: as quatro etapas de uma aprendizagem. Curitiba: Ed. UTFPR, 2012.

\section{Como referenciar este artigo}

GASPARELO, Rayane Regina Scheidt; SCHNECKENBERG, Marisa. Formação continuada de professores: racionalidade técnica versus desenvolvimento profissional. Revista on line de Política e Gestão Educacional, Araraquara, v. 21, n. esp.2, p. 11191134, nov. $2017 . \quad$ Disponível em: <http://dx.doi.org/10.22633/rpge.v21.n.esp2.2017.10185>. E-ISSN:1519-9029.

Submetido em: 30/07/2017

Aprovado em: 21/09/2017 